Nevena D. Stevanovic

Associate Professor University of Belgrade

Faculty of Mechanical Engineering

Vladan D. Djordjevic

Member of the

Academy of sciences and arts Serbian academy of sciences and arts

\section{An Exact Analytical Solution for the Second Order Slip-Corrected Reynolds Lubrication Equation}

We derive a general slip-corrected compressible Reynolds lubrication equation, valid for any choice of the slip velocities, and show that it possesses the exact analytical solution. It is obtained by a suitable transformation of the dependent variable, and it yields both the pressure distribution in the bearing and the mass flow rate through it. It can be usefully applied for testing the other, experimental or numerical results obtained under the same or similar physical conditions, against this solution.

Keywords: microbearing, Reynolds lubrication equation, analytical solution, second order slip velocity.

\section{INTRODUCTION}

New fabrication techniques developed during the last decade or so, in particular the production of micro-scale devices, have led to an intense application of microelectro-mechanical systems (MEMS) technologies in our everyday life [1]. On the other hand MEMS technologies have brought several new problems to the scientific community. In particular, in fluid mechanics it turns out that the behaviour of flow in a micro-scale device is not necessarily the same as the one experienced in the macroscopic world. For example, in the context of compressible gas dynamics rarefaction effects must be accounted for, and their presence can be recognized by the values attained by the Knudsen number $K n$. As a rule of thumb, for $K n<10^{-2}$ the continuum hypothesis hold and the flow is described by the Navier-Stokes equations using conventional no-slip boundary conditions. In the range $10^{-2}<K n<10^{-1}$ the Navier-Stokes equations are still valid, provided slip boundary conditions are implemented at the walls of the flow boundaries (slip-flow regime). In the range $10^{-1}<K n<10$ (transitional flow regime) the NavierStokes equations break down, and some "higher-order", more complex, Burnett equations are necessary, or the individual particle-based direct simulation Monte Carlo (DSMC) approach is to be employed. Finally, for $K n>10$.the flow has to be treated as a free molecular flow amenable to the methods of kinetic theory of gases.

Most MEMS devices in use today operate in the slip-flow regime. That is why the most of the literature referring to these problems is devoted to the modelling of the slip boundary conditions at the walls (for an excellent review on these problems s. [2]). We note in passing at this point that there are several attempts in the literature to modify the existing slip-boundary

Received: September 2013, Accepted: December 2013

Correspondence to: Nevena Stevanovic

Faculty of Mechanical Engineering,

Kraljice Marije 16, 11120 Belgrade 35, Serbia

E-mail: nstevanovic@mas.bg.ac.rs

doi:10.5937/fmet1501016S

(C) Faculty of Mechanical Engineering, Belgrade. All rights reserved conditions in a purely empirical way, so as to encounter all regimes mentioned above - the entire Knudsen number regime [3].

Roughly speaking all rarefied gas flows appearing in MEMS devices can be divided into the pressure driven and the shear driven flows. Typical pressure driven flow is a flow through a channel or a pipe. In contrast to the classical, incompressible flow case with no-slip boundary conditions, such a flow in rarefied gas dynamics context is characterized by a nonlinear pressure drop in the direction of flow. The nonlinear first order differential equation governing the pressure distribution in a channel or a pipe can be readily derived from the basic flow equations and solved analytically exactly for the so-called second-order slip boundary conditions [4].

Typical shear driven flows are the Coutte flow or any other flow appearing in a problem of gas lubrication. The pressure distribution in a gas lubricated bearing is governed by the so-called Reynolds equation. Under certain conditions it can be readily derived from the basic flow equations for both no-slip and slip boundary conditions [5-7]. This equation is also nonlinear. To the best of our knowledge only one exact analytical solution of this equation exists and it is presented in [8]. It was found by suitably transforming the independent variable in the slip-corrected Reynolds equation.

In this paper it is shown that the same slip-corrected Reynolds equation can be also analytically solved by appropriate transformation of the dependant variable (pressure) and by the direct integration of the derived differential equation in the closed form by quadratures. The validity of the solution is proved by comparison with numerical results available in the literature.

\section{DERIVATION OF THE GENERAL SLIP- CORRECTED REYNOLDS EQUATION}

For completeness of the presentation we will first briefly derive a general Reynolds equation - the equation valid for an arbitrary model of the slip velocity. We will consider the lubrication problem depicted in Fig. 1. 


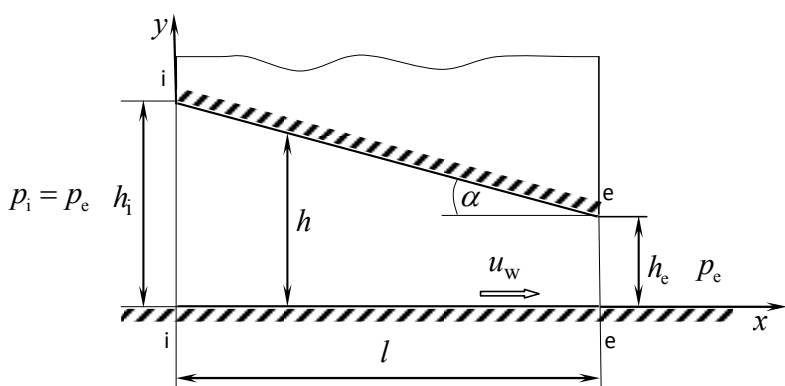

Figure 1. Microbearing geometry

Within the well known approximations made at the derivation of the Reynolds equation $[5,6]$, the extremely simplified Navier-Stokes equations expressing the balance between the pressure forces and highest viscous forces only, reads:

$$
\frac{\partial^{2} u}{\partial y^{2}}=\frac{1}{\mu} \frac{\mathrm{d} p}{\mathrm{~d} x}
$$

where $p(x)$ is the pressure and $\mu=$ const. is the gas viscosity, while the other denotations clearly seen in Fig.1. The equation (1) should be solved with the following boundary conditions:

$$
y=0: u=u_{0}(x) ; \quad y=h(x): u=u_{1}(x),
$$

where $u_{0}(x)$ and $u_{1}(x)$ are arbitrary slip velocities. The solution of equation (1) with boundary conditions (2) is easily found to be:

$$
u=\frac{h^{2}}{2 \mu} \frac{\mathrm{d} p}{\mathrm{~d} x} \frac{y^{2}}{h^{2}}-\left(u_{0}-u_{1}+\frac{h^{2}}{2 \mu} \frac{\mathrm{d} p}{\mathrm{~d} x}\right) \frac{y}{h}+u_{0} .
$$

This solution is further used in the continuity equation that expresses the constancy of the mass flow rate $\dot{M}$ through the bearing:

$$
\dot{M}=\int_{0}^{h} \rho u \mathrm{~d} y=\rho(x) h(x) \int_{0}^{1} u(\eta) \mathrm{d} \eta=\text { const } .
$$

where $\eta=y / h$ and $\rho(x)$ is the variable gas density. Inserting (3) into (4) one gets an equation governing the pressure distribution in the bearing. At that, when the independent variable $x$ is replaced by $h(x)$ (s. Fig.1) and the equation of state for an ideal gas $\rho=p /(\mathrm{R} T)$, where $\mathrm{R}$ is the gas constant and $T$ is the temperature (presumably constant) is utilized, it reads

$$
\dot{M}=-\frac{h^{3}}{12 \mu \mathrm{R} T} \frac{\mathrm{d} h}{\mathrm{~d} x} p \frac{\mathrm{d} p}{\mathrm{~d} h}+\frac{u_{0}+u_{1}}{2 \mathrm{R} T} h p
$$

For the solution of this equation two boundary conditions are available (s. Fig.1): $h=h_{\mathrm{i}}: p=p_{\mathrm{i}}=p_{\mathrm{e}}$; $h=h_{\mathrm{e}}: p=p_{\mathrm{e}}$, where indices $\mathrm{i}$ and e refer to inlet and exit bearing cross sections respectively. Any type of integration of this equation (analytical or numerical) as a result yields not only the already mentioned pressure distribution, but also the mass flow rate $\dot{M}$, which is not know beforehand. In what follows it is instructive to write (5) and the belonging boundary conditions in nondimensional form. We introduce the non-dimensional quantities in the following way (s. Fig.1): $X=x / l$, $H=h / h_{\mathrm{e}}, P=p / p_{\mathrm{e}}, U_{0}=u_{0} / u_{\mathrm{w}}, U_{1}=u_{1} / u_{\mathrm{w}},\left(u_{\mathrm{w}}\right.$ is the velocity of the infinite plate positioned at $y=0)$, so that the equation (5) with its boundary conditions becomes:

$$
\begin{gathered}
-\frac{1}{\Lambda} \frac{\mathrm{d} H}{\mathrm{~d} X} H^{3} P \frac{\mathrm{d} P}{\mathrm{~d} h}+\left(U_{0}+U_{1}\right) H P=\frac{\dot{M}}{\dot{M}_{\mathrm{C}}} \\
H=H_{\mathrm{i}}=\frac{h_{\mathrm{i}}}{h_{\mathrm{e}}}>1: P=1 ; H=1: P=1
\end{gathered}
$$

In there $\Lambda=\frac{6 \mu u_{\mathrm{w}} l}{p_{\mathrm{e}} h_{\mathrm{e}}^{2}}$ is the bearing number and $\dot{M}_{\mathrm{C}}=\frac{p_{\mathrm{e}} h_{\mathrm{e}} u_{\mathrm{w}}}{2 \mathrm{R} T}$ is the mass flow rate in a Couette flow.

Before proceeding further we will evaluate the sum of the slip velocities $U_{0}+U_{1}$ for the case of the second order boundary conditions. For the problem considered herein they are [2]:

$$
\begin{aligned}
& u_{0}=u_{\mathrm{w}}+\left.\mathrm{A}_{1} \lambda \frac{\partial u}{\partial y}\right|_{y=0}-\left.\mathrm{A}_{2} \lambda^{2} \frac{\partial^{2} u}{\partial y^{2}}\right|_{y=0} \\
& u_{1}=-\left.\mathrm{A}_{1} \lambda \frac{\partial u}{\partial y}\right|_{y=h}-\left.\mathrm{A}_{2} \lambda^{2} \frac{\partial^{2} u}{\partial y^{2}}\right|_{y=h}
\end{aligned}
$$

where, in addition to denotations already used earlier, $\lambda$ is the molecular free path, and $\mathrm{A}_{1}$ and $\mathrm{A}_{2}$ are some constant corrective factors (first and second order slip coefficients). For an isothermal flow $\lambda$ is simply inversely proportional to the pressure, thus depend on $x$ only [9]. The first and second order slip coefficients, $\mathrm{A}_{1}$ and $\mathrm{A}_{2}$, are differently defined by several authors in the literature. Schamberg [10] predicted theoretical values for the slip coefficients as $A_{1}=1, A_{2}=5 \pi / 12$, Deissler [11] as $A_{1}=1, A_{2}=9 / 8$, Hsia and Domoto [12] as $A_{1}=1, A_{2}=1 / 2$, while Beskok et al. [4] found that $A_{1}=1, A_{2}=-1 / 2$. The review of the second order velocity slip boundary conditions are presented by Barber and Emerson [2] and Lockerby et al. [13] and according to them there is no consensus concerning the values of $A_{1}$ and $A_{2}$.

Careful evaluation of slip velocities (8) by using the general velocity field (3) yields now the following expression for the desired sum of the non-dimensional slip velocities:

$$
U_{0}+U_{1}=1-\frac{6}{\Lambda} \frac{\mathrm{d} H}{\mathrm{~d} X} H^{2} \frac{\mathrm{d} P}{\mathrm{~d} H}\left(\mathrm{~A}_{1} K n+2 \mathrm{~A}_{2} K n^{2}\right)
$$

where $K n$ is the local value of the Knudsen number:

$$
K n=\frac{\lambda}{h}=\frac{K n_{\mathrm{e}}}{P H}
$$


and $K n_{\mathrm{e}}=\lambda_{\mathrm{e}} / h_{\mathrm{e}}$ is its value at the exit cross section. If the upper boundary in Fig. 1 is in the form of an inclined plate, we will have: $\mathrm{d} H / \mathrm{d} X=-\left(H_{\mathrm{i}}-1\right)$, and the equation (6) will finally attain the form:

$$
\begin{aligned}
& \frac{H_{\mathrm{i}}-1}{\Lambda} H^{3} P \frac{\mathrm{d} P}{\mathrm{~d} H}\left[1+6 K n\left(\mathrm{~A}_{1}+2 \mathrm{~A}_{2} K n\right)\right]+ \\
& +P H=\frac{\dot{M}}{\dot{M}_{\mathrm{C}}} .
\end{aligned}
$$

\section{ANALYTICALLY EXACT SOLUTION OF THE SLIP- CORRECTED REYNOLDS LUBRICATION EQUATION}

Suitable transformation of the dependent variable $P$ that enables us to get analytically exact solution of equation (11) with the boundary conditions (7) reads:

$$
\Pi=\frac{1}{P H}
$$

A simple physical meaning can be given to the new dependent variable $\Pi(H)$. It follows from (10) that $\Pi=K n / K n_{\mathrm{e}}$, i.e. it is the ratio between the local value of the Knudsen number and its exit value. Now the equation (11) is transformed into:

$$
\frac{H_{\mathrm{i}}-1}{\Lambda}\left(H \frac{\mathrm{d} \Pi}{\mathrm{d} H}+\Pi\right)\left[1+F\left(K n_{\mathrm{e}} \Pi\right)\right]=\Pi^{2}(1-m \Pi)
$$

where

$$
F\left(K n_{\mathrm{e}} \Pi\right)=6 K n_{\mathrm{e}} \Pi\left(\mathrm{A}_{1}+2 \mathrm{~A}_{2} K n_{\mathrm{e}} \Pi\right)
$$

and $m=\dot{M} / \dot{M}_{\mathrm{C}}$. At the same time boundary conditions (7) become:

$$
\begin{gathered}
H=H_{\mathrm{i}}>1: \Pi=1 / H_{\mathrm{i}} ; \\
H=1: \Pi=1 .
\end{gathered}
$$

We tested the form of equation (13) against some other models of slip velocities existing in the literature and widely used [2] and obtained the same form of the equation for $\Pi(H)$, with $F\left(K n_{\mathrm{e}} \Pi\right)=F(K n)$ varying from model to model. However, in all cases tested $F(0)=0$ and, as expected, the equations (11) and (13) reduce to their well known form for a no-slip compressible flow through a bearing.

Equation (13) can be written in the form in which variables $H$ and $\Pi$ are separated:

$$
\frac{\mathrm{d} H}{H}=\frac{\left[1+F\left(K n_{\mathrm{e}} \Pi\right)\right] \mathrm{d} \Pi}{\frac{\Lambda}{H_{\mathrm{i}}-1} \Pi^{2}(1-m \Pi)-\Pi\left[1+F\left(K n_{\mathrm{e}} \Pi\right)\right]}
$$

and its solution can be obtained by quadratures. For example, when applying the second of boundary conditions (15) we get:

$$
\ln H=\int_{\Pi}^{1} \frac{\left[1+F\left(K n_{\mathrm{e}} t\right)\right] \mathrm{d} t}{t\left[1+F\left(K n_{\mathrm{e}} t\right)-\frac{\Lambda}{H_{\mathrm{i}}-1} t(1-m t)\right]} .
$$

where $t$ is dummy variable.

Application of the first of boundary conditions (15) in (17) leads to:

$$
\ln H_{\mathrm{i}}=\int_{1 / H_{\mathrm{i}} t}^{1} \frac{\left[1+F\left(K n_{\mathrm{e}} t\right)\right] \mathrm{d} t}{\left[1+F\left(K n_{\mathrm{e}} t\right)-\frac{\Lambda}{H_{\mathrm{i}}-1} t(1-m t)\right]}
$$

The expression (18) serves for the determination of $m$ by iterations, provided other parameters $\left(H_{\mathrm{i}}, \Lambda, K n_{\mathrm{e}}\right)$ are known, while (17) serves for the determination of $\Pi(H)$, and thus $P(H)$.

For $F\left(K n_{\mathrm{e}} \Pi\right)$ given by the second order slip velocity (14) the integral (17) can be found as:

$$
\ln H=\int_{\Pi}^{1} \frac{1+6 \mathrm{~A}_{1} K n_{\mathrm{e}} t+12 \mathrm{~A}_{2} K n_{\mathrm{e}}^{2} t^{2}}{t\left(1+\mathrm{C}_{1} t+\mathrm{C}_{2} t^{2}\right)} \mathrm{d} t
$$

where $\quad \mathrm{C}_{1}=6 \mathrm{~A}_{1} K n_{\mathrm{e}}-\Lambda /\left(H_{\mathrm{i}}-1\right) \quad$ and $\mathrm{C}_{2}=12 \mathrm{~A}_{2} K n_{\mathrm{e}}^{2}+m \Lambda /\left(H_{\mathrm{i}}-1\right)$. There are two possible solutions for integral (19). First, if $C_{1}^{2}-4 C_{2} \geq 0$ the solution is

$$
\begin{aligned}
& \ln H=-\ln \Pi-\frac{m \Lambda}{2 \mathrm{C}_{2}\left(H_{\mathrm{i}}-1\right)} \ln \left(\frac{\mathrm{C}_{2}+\mathrm{C}_{1}+1}{\mathrm{C}_{2} \Pi^{2}+\mathrm{C}_{1} \Pi+1}\right) \\
& +\frac{\Lambda}{H_{\mathrm{i}}-1}\left(1+\frac{m \mathrm{C}_{1}}{2 \mathrm{C}_{2}}\right) \frac{1}{\sqrt{\mathrm{C}_{1}^{2}-4 \mathrm{C}_{2}}} \times \\
& \times \ln \frac{\left(2 \mathrm{C}_{2}+\mathrm{C}_{1}-\sqrt{\mathrm{C}_{1}^{2}-4 \mathrm{C}_{2}}\right)\left(2 \mathrm{C}_{2} \Pi+\mathrm{C}_{1}+\sqrt{\mathrm{C}_{1}^{2}-4 \mathrm{C}_{2}}\right)}{\left(2 \mathrm{C}_{2}+\mathrm{C}_{1}+\sqrt{\mathrm{C}_{1}^{2}-4 \mathrm{C}_{2}}\right)\left(2 \mathrm{C}_{2} \Pi+\mathrm{C}_{1}-\sqrt{\mathrm{C}_{1}^{2}-4 \mathrm{C}_{2}}\right)}
\end{aligned}
$$

where parameter $m$ is found by putting the first of boundary conditions (15) in into eq. (20)

$$
\begin{gathered}
m=\frac{2 \mathrm{C}_{2}}{\sqrt{\mathrm{C}_{1}^{2}-4 \mathrm{C}_{2}}}\left(1+\frac{m \mathrm{C}_{1}}{2 \mathrm{C}_{2}}\right) \frac{1}{\ln \left[\frac{h_{\mathrm{i}}^{2}\left(\mathrm{C}_{2}+\mathrm{C}_{1}+1\right)}{\mathrm{C}_{2}+h_{\mathrm{i}} \mathrm{C}_{1}+h_{\mathrm{i}}^{2}}\right]} \times \\
\times \ln \frac{\left(2 \mathrm{C}_{2}+\mathrm{C}_{1}-\sqrt{\mathrm{C}_{1}^{2}-4 \mathrm{C}_{2}}\right)\left(2 \mathrm{C}_{2} / h_{\mathrm{i}}+\mathrm{C}_{1}+\sqrt{\mathrm{C}_{1}^{2}-4 \mathrm{C}_{2}}\right)}{\left(2 \mathrm{C}_{2}+\mathrm{C}_{1}+\sqrt{\mathrm{C}_{1}^{2}-4 \mathrm{C}_{2}}\right)\left(2 \mathrm{C}_{2} / h_{\mathrm{i}}+\mathrm{C}_{1}-\sqrt{\mathrm{C}_{1}^{2}-4 \mathrm{C}_{2}}\right)}
\end{gathered}
$$

For the case $C_{1}^{2}-4 C_{2}<0$ the solution of eq. (19) is

$$
\begin{aligned}
\ln H= & -\ln \Pi-\frac{m \Lambda}{2 \mathrm{C}_{2}\left(H_{\mathrm{i}}-1\right)} \ln \left(\frac{\mathrm{C}_{2}+\mathrm{C}_{1}+1}{\mathrm{C}_{2} \Pi^{2}+\mathrm{C}_{1} \Pi+1}\right) \\
& +\frac{2 \Lambda}{H_{\mathrm{i}}-1}\left(1+\frac{m \mathrm{C}_{1}}{2 \mathrm{C}_{2}}\right) \frac{1}{\sqrt{4 \mathrm{C}_{2}-\mathrm{C}_{1}^{2}}} \times
\end{aligned}
$$




$$
\times \operatorname{arctg} \frac{(1-\Pi) \sqrt{4 \mathrm{C}_{2}-\mathrm{C}_{1}^{2}}}{2\left(1+\mathrm{C}_{2} \Pi\right)+\mathrm{C}_{1}(1+\Pi)}
$$

Now parameter $m$ is found by putting the first of boundary conditions (15) into eq. (22)

$$
\begin{aligned}
m= & \frac{4 \mathrm{C}_{2}+2 m \mathrm{C}_{1}}{\sqrt{4 \mathrm{C}_{2}-\mathrm{C}_{1}^{2}}} \frac{1}{\ln \frac{H_{\mathrm{i}}^{2}\left(\mathrm{C}_{2}+\mathrm{C}_{1}+1\right)}{\mathrm{C}_{2}+H_{\mathrm{i}} \mathrm{C}_{1}+H_{\mathrm{i}}^{2}}} \times \\
& \times \operatorname{arctg} \frac{\left(H_{\mathrm{i}}-1\right) \sqrt{4 \mathrm{C}_{2}-\mathrm{C}_{1}^{2}}}{2\left(H_{\mathrm{i}}+\mathrm{C}_{2}\right)+\mathrm{C}_{1}\left(H_{\mathrm{i}}+1\right)}
\end{aligned}
$$

The pressure distribution, which is obtained by eqs. (20) and (21) or by eqs. (22) and (23), is defined by the bearing number $\Lambda$, the reference Knudsen number $K n_{\mathrm{e}}$, and the ratio of the inlet and exit microbearing height $H_{\mathrm{i}}$. First, parameter $m$ is determined from eqs. (21) or (23) iteratively by supposing the initial value for $m$ taking into account whether $\mathrm{C}_{1}^{2}-4 \mathrm{C}_{2}$ is positive or negative. Although variable $\Pi$ could not be explicitly expressed from eqs. (20) and (22), correlation between $\Pi$ and $H$ is completely defined by eqs. (20) and (22). According to the boundary conditions (15), the value of $\Pi$ is between $\Pi=1 / H_{\mathrm{i}}$ at the bearing inlet and $\Pi=1$ at the bearing outlet. For the $\Pi$ values in that range, appropriate values of $H$ are found from eq. (20) or (22) while the coordinate $X$ is determined from the channel cross section varying function. Then, for each pair of $\Pi$ and $H$ the pressure is defined as $P=1 /(\Pi H)$.

In Fig. 2 the pressure distribution is presented for bearing number $\Lambda=1$. Results are obtained for the ratio of the inlet and outlet microbearing height $H_{\mathrm{i}}=2$ and three $K n_{\mathrm{e}}$ values $\left(K n_{\mathrm{e}}=0.1, K n_{\mathrm{e}}=0.2\right.$ and $\left.K n_{\mathrm{e}}=0.5\right)$. The presented results show the reliability of obtained analytical solution for the slip flow regime $\left(K n_{\mathrm{e}}=0.1\right)$, as well as for the part of the transitional regime $\left(K n_{\mathrm{e}}=0.2, K n_{\mathrm{e}}=0.5\right)$. The second order boundary condition defined by Schamberg [10] leads to the best fit of the analytical solution with the numerical solution of the Boltzman equation obtained by Fukui and Kaneko [15] in the slip regime $\left(K n_{\mathrm{e}}=0.1\right)$, while for the beginning of the transition flow regime $\left(K n_{\mathrm{e}}=0.2\right)$ Deissler [11] boundary condition is the most appropriate. For the higher Knudsen number value $\left(K n_{\mathrm{e}}=0.5\right)$ the analytical solution obtained with Hsia and Domoto [12] slip coefficients value is in good agreement with the numerical solution of the Boltzmann equation. Thus, it is confirmed that the analytical solution is valid even for a higher Knudsen number value up to $K n_{\mathrm{e}}=0.5$.

For all results presented in Fig. 2 Beskok et al. [4] boundary condition gives pronounced deviation from the Fukui and Kaneko [15] results.

In Figs. 2 the analytical solutions which correspond to the Maxwell first order boundary condition are also depicted. It is obvious that Schamberg [10], Daissler
[11] and Hsia and Domoto [12] second order boundary conditions provide higher accuracy then the Maxwell [14] first order boundary condition.

a)

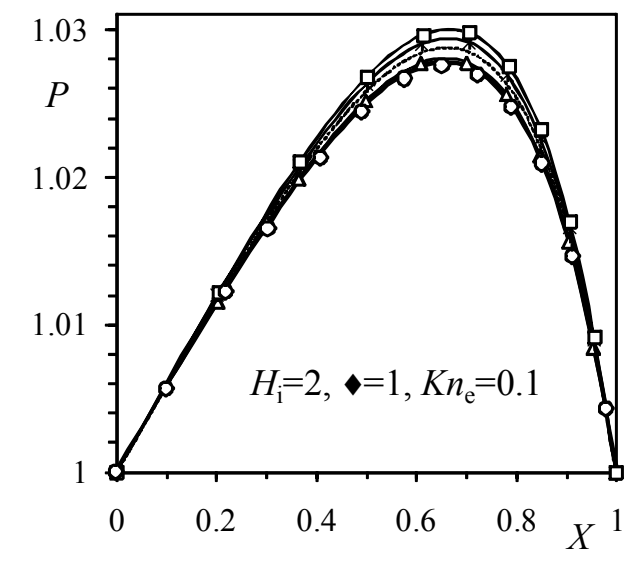

b)
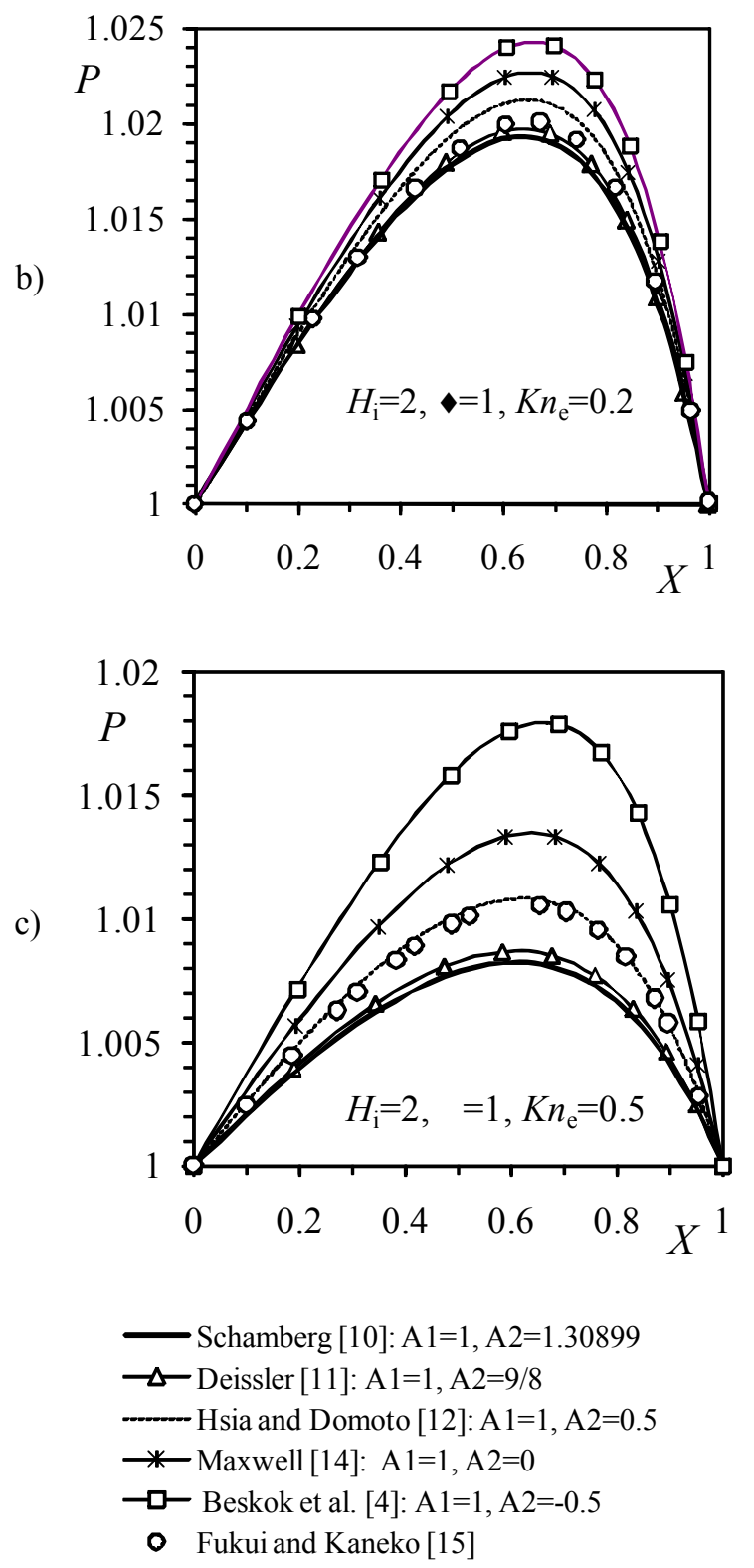

Figure 2. Pressure distribution in the microbearing obtained with presented analytical solution and different slip coefficients in the boundary conditions and with Boltzmann equation [15] for $\Lambda=1, H_{\mathrm{i}}=2$ and: a) $K n_{\mathrm{e}}=0.1$, b) $K n_{\mathrm{e}}=0.2$, c) $K n_{\mathrm{e}}=0.5$. 


\section{CONCLUSION}

This paper presents a new approach to the derivation of the analytical solutions of the compressible slip corrected Reynolds lubrication equation and the classical compressible Reynolds lubrication equation for continuum flow conditions. The first analytical solution of the isothermal steady compressible quasiunidirectional lubrication problem was first reported in the open literature in [8]. It was achieved by the proper change of independent variable. Here presented new approach is based on the suitable transformation of the dependent variable (pressure). The obtained differential equation written in the form in which variables $H$ and $\Pi$ are separated (eq. 16) can be transformed in the differential equation with separated variables presented by equation (2.14) in [8]. This indicates that despite the fact that final analytical solutions obtained by transformations of the dependent and independent variable don't have the same form, the both solutions give the same result. Beside results presented in Fig. 2, more extensive validation of this analytical solution was already presented in [8] by comparison of the analytically obtained results with available numerical results. Namely, the slip flow results for a wide range of Knudsen number and the continuum flow conditions, provided by the general analytical solution from this paper and [8], are in excellent agreement with Fukui and Kaneko [15] numerical solution of the Boltzmann equation.

\section{ACKNOWLEDGMENT}

This work was supported by the Ministry of Science of the Republic of Serbia (Grant 174014)

\section{REFERENCES}

[1] Gad-El-Hak, M.: The MEMS Handbook, CRC Press, Florida, 2002.

[2] Barber, R.E. and Emerson D.R.: Challenges in modelling gas-phase flow in microchannels: from slip to transition, Heat Transfer Engineering, Vol. 27, pp. 3-12, 2006.

[3] Bahukudumbi, $\mathrm{P}$ and Beskok, A.: A phenomenological lubrication model for the entire Knudsen regime, J. Micromech And Microeng, Vol. 13, pp. 873-884, 2003.

[4] Beskok, A., Karniadakis, G.E. and Trimmer, W.: Rarefaction and compressibility effects in gas microflows, Trans. ASME - J. Fluids Eng, Vol. 118, No. 3, pp. 448-456, 1996.

[5] Szeri, A.Z.: Fluid film lubrication: theory and design, Cambridge University Press; 1998.

[6] Hamrock, B.J., Schmid, S.R. and Jacobson, B.O.: Fundamentals of fluid film lubrication, Marcel Dekker Inc., New York, 2004.

[7] Breuer, K.: Lubrication in MEMS, in: Gad-El-Hak, M. (Ed.): The MEMS Handbook, CRC Press, Florida, 2002.
[8] Stevanovic, N.D. and Djordjevic, V.D.: The exact analytical solution for the gas lubricated bearing in the slip and continuum flow regime, Publications de l'Institute Matematique, Vol. 91, No. 105, pp. 83-93, 2012.

[9] Karniadakis, G. and Beskok, A.: Micro Flows: Fundamentals and simulation, Springer, New York, 2002.

[10] Schamberg, R.: The fundamental differential equations and the boundary conditions for high speed slip-flow, and their application to several specific problems, $\mathrm{PhD}$ Thesis, California Institute of Technology; 1947.

http://resolver.caltech.edu/CaltechETD:etd12272004-161736

[11] Deissler, R.G.: An analysis of second-order slip flow and temperature-jump boundary conditions for rarefied gases, J. Heat Mass Transfer, Vol: 7, pp. 681-694, 1964.

[12]Hsia, Y. and Domoto, G.: An experimental investigation of molecular rarefaction effects in gas-lubricated bearings at ultra low clearances, J. Lubr. Technol., Vol. 105, pp. 120-130, 1983.

[13] Lockerby, D.A., Reese, J.M. and Emerson, D.R. and Barber, R.W.: Velocity boundary condition at solid wall in rarefied gas calculation, Phys. Rev. E, Vol. 70: 017303, 2004.

[14] Maxwell, J.C.: On stresses in rarefied gases arising from inequalities of temperature, Phil. Trans. R. Soc. London Vol. 170: 231-56, 1879.

[15] Fukui, S., Kaneko, R.: Analysis of ultra-thin gas film lubrication based on linearized Boltzmann equation. First report-derivation of a generalized lubrication equation including thermal creep flow, J. Tribol., Vol. 110, pp. 253-262,1988.

\section{ТАЧНО АНАЛИТИЧКО РЕШЕЊЕ РЕЈНОЛДСОВЕ ЈЕДНАЧИНЕ ПОДМАЗИВАҢА ЗА СТРУЈАҢЕ ГАСА СА КЛИЗАЊЕМ}

\section{Невена Д. Стевановић, Владан Д. Ђорђевић}

Изведена је општа Рејнолдсова једначина подмазивања за услове струјања са клизањем применом општих граничних услова клизања другог реда и показано је да она има тачно аналитичко решење. Решење је добијено тансформацијом зависно променљиве што је довело до могућности аналитичког прорачуна расподеле притиска и масеног протока у микролежају. На тај начин, поређењем са датим аналитичким решењем омогућена је провера експерименталних и нумеричких резултата за струјање гаса у микролежајима. 